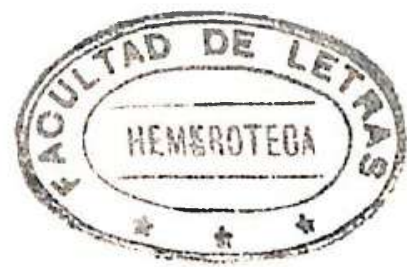

\title{
Semiótica de la imagen artística
}

\author{
GULLERMO DANINO RIBATTO
}

Es extremadamente dificil hablar del sentido y decir algo sensato.

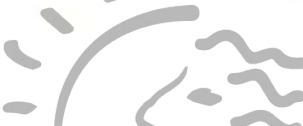

A. J. Greimas

La semiótica se define como ciencia de la significación y, por derecho a su objetivo, se propone el estudio de todos los sistemas de signos utilizados por el hombre en tanto procesos de significación o en tanto códigos de comunicación.

El Arte, clase particular definida por cada cultura, constituye una estructura social que vehicula sentidos codificados de un modo particular. Nuestra aceptación del concepto $Y$ y del término suponen, de nuestra parte, una admisión al menos operativa de la definición de arte en el universo cultural de Occidente. Este concepto y esta definición no pueden ser sustentados desde una reflexión semiótica pura. En efecto, la calidad de belleza y no-belleza, con todos sus grados o matices, corresponde a una categorización externa al contenido semiótico. Es más, la semiótica "suscita la crisis" del concepto mismo de arte como pre-juicio cultural más aceptado por las vías de la autoridad social que por las de una definición interna de los macrosistemas.

La clasificación "imagen artística" corresponde, por lo tanto, desde su formulación a un criterio extrasemiótico digno de ser revisado. Es el caso paralelo de la literatura respecto de la lengua; la determinación de estas distinciones corresponde a presupuestos culturales y no al modo preciso de estructurarse el sentido, ni a la consideración del sentido mismo.

Porque todo sentido se transmite por medio de un sistema construido (struere: construir $y$, por tanto, estructura), el análisis 
de los procedimientos significadores es tarea fundamental de la semiótica.

Este trabajo exige la determinación de las unidades significativas, de su organización y distribución, de sus niveles y jerarquías, de la conformación de los conjuntos menores y mayores, de las relaciones intertextuales en el marco general de la cultura que da origen al texto sometido a análisis.

El arte, y en nuestro caso la imagen artística, constituye, en un sentido lato, un verdadero sistema de comunicación en cuanto transmite una información codificada en un sistema de signos, soportada físicamente por un canal o medium, procedente de un emisor o firente del mensaje que llega al receptor-destinatario que posee la competencia de la decodificación conveniente.

Pero en sentido estricto, las imágenes artísticas conforman procedimientos de significación o de pura "mostración" pues, a diferencia de la comunicación, carecen de interlocutor o receptor definido, no se produce el intercambio intersubjetivo $\mathrm{y}$, principalmente, el significante es considerado en sí mismo como objetivo de una elaboración particular. Esta elaboración define precisamente toda actividad artística. Este significante es signo de sí y de su contenido.

En esta última observación reside el peligro de las interpretaciones deficientes. Sin una perspectiva semiótica el teórico del arte considera tan sólo la construcción formal, la proyección de disposiciones psíquicas o fisiológicas del autor, el reflejo de realidades ideológicas, económicas, sociales y culturales.

La obra de arte posee el carácter de signo y su estatuto particular se apoya en la relación con un sistema que no es el de la lengua ni el de ningún otro código establecido. Existe, por consiguiente, un mecanismo artístico en nuestra cultura que hace del signo ordinario (lingüístico, visual, etc.) un signo."de otra cosa", un sistema particular.

\section{A. La imagen artística}

Para concretar nuestras observaciones sobre el fenómeno visual en el arte, nos centraremos en la consideración de la "pintura artística", conforme a la tradicional clasificación de nuestra cultura.

En el marco general de la comunicación en sentido amplio, una pintura se inscribe en el centro del proceso:

Emisor

I

Artista
Canal

2

(Mensajes)
Receptor

3

Espectador

Público 
A. Respecto del conocimiento del código, la problemática puo de esquematizarse del modo siguiente (1).

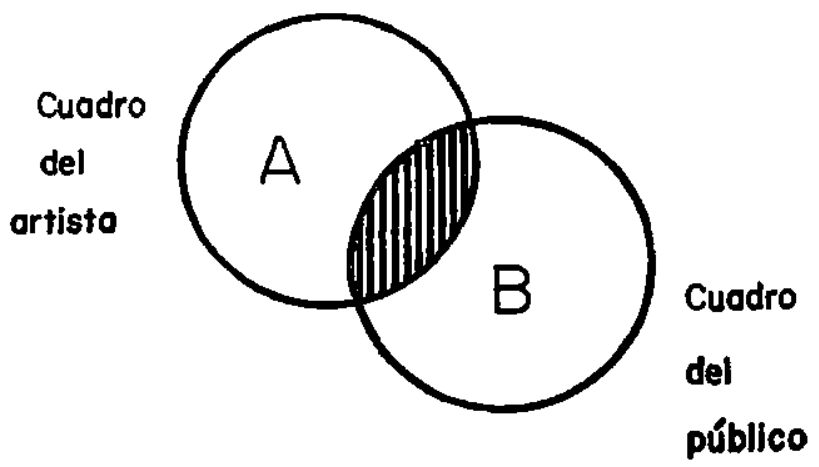

Repertorios

La observación del esquema nos conduce a las siguientes roflexiones:

1) La técnica $u$ oficio es objeto de estudio y de transformación para el artista. El público ignora, de ordinario, las condiciones físicas de la produccióni sin embargo éstas son transmitidas con eficacia al conocedor.

En la comunicación lingüística un fenómeno paralelo se produce cuando las condiciones físicas de la enunciación son productoras de sentido: la entonación el titubeo, el carraspeo, el timbre, etc.

2) La inspiración original es de naturaleza completamente diferente a la del objeto resultante. Aquella es imaginación y proyecto, creación en proceso, corrección, afinamiento, indecisión y decisión.

La poesía, de manera semejante, no corresponde exactamente a la emoción por transmitirse, como corresponde el lenguaje coloquial al deseo del hablante.

3) El concepto de arte, con las complicadas presuposiciones que suele comportar en cada artista, no coincide sino pocas veces on la conciencia del público.

La comunicación lingüística, por el contrario, pone en acción definiciones instrumentales aceptadas por la mayoría y mantiene su estatuto sin dificultad $a$ través de los cambios formales.

p. 17 .

(1) Abraham Moles. Art et ordinateur. Paris, Casterman, 1971, 
4) Cada objeto artístico (cada pintura) crea su propia codificación tomando, naturalmente, las posibilidades instrumentales existentes, siempre diferentes, con la intención expresa de lo inédito en el trabajo del significante.

La lengua instrumentaliza lo sistemático y no dispone sino de un pequeño margen de innovación, manejado con parsimonia por un número proporcionalmente reducido de usuarios.

5) Las circunstancias de la enunciación son decisivas para la decodificación correcta del enunciado. La imagen es por sí misma incapaz de marcar con "shifters", como lo hace la lengua, a no ser por las reglas de la perspectiva que condicionan las formas y los matices al eje visual del espectador $\mathrm{y}$, simultáneamente, al del artista. Esta colocación equivaldría a ciertas deixis lingüísticas de función espacial.

6) Al modo de las lenguas concretas que no utilizan, por ejemplo, todas las posibilidades fonéticas sino que seleccionan sistemáticamente las suficientes, cada obra de arte actualiza algunos de los posibles pictóricos de acuerdo a la técnica de la época y a la elección del artista. Esta selección puede marcar la ignorancia de una técnica (la perspectiva en Egipto) o la voluntad consciente de un estilo (ausencia del negro entre los impresionistas, la "imperfección" figurativa entre los naïfs, la no-figuración entre los abstractos).

\section{B. Sistemática de la imagen pictórica}

El pintor que desea expresar y transmitir dispone de un arsenal de recursos combinatorios. A partir de esas unidades abstrac-

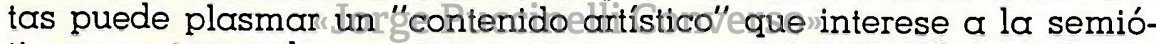
tica, construyendo un sistema inmanente por selección y presentación de formas capaces de significar.

De acuerdo con la definición funcional de la semiótica como

jerarquía que puede someterse a análisis y cuyos elementos pueden ser determinados por las relaciones recíprocas (2).

podemos intentar una descripción de los recursos pictóricos posibles para la conformación de una estructura portadora de sentido.

\section{a) Primer nivel: CODIGOS OPTICOS}

Este nivel manipula unidades y combinaciones del repertorio exclusivamente pictórico. Las unidades mínimas no significativas,

(2) A. J. Greimas. Du sens. Paris, Seuil, 1970, p. 22. 
que llamaremos optemas, se localizan en el grupo pictórico simple. Los semas corresponden al grupo pictórico complejo.

\section{Pictórico simple: optemas}

I. Luminosidad, organizada a partir de la oposición luz/obscuridad, oposición que permite una cierta graduación cuyos extremos deben determinarse en cada caso concreto.

II. Precisión que permite la distinción nítido/difuso como optema para usos diferentes.

III. Cromaticidad determinada por la frecuencia de las ondas luminosas, instituida en cada caso particular a partir de la combinación de dos o más colores opuestos y de colores secundarios más o menos estructurados en un eje cromático.

IV. Espacialidad construida desde el optema superficie en oposición a los límites.

V. Linearidad o formas establecidas por oposición: rectas/curvas, simples/complejas, marcadas/no marcadas, en el diseño considerado aún no capaz de significar.

Si toda operación significativa presupone funcionalmente la existencia de una relación que constituya el signo, en este nivel del análisis de optemas cada unidad es sólo signo de sí mismo y. por lo general, al servicio de otra estructura mayor que remite $\alpha$ un significado. Un optema no debe, por tanto, por definición, significar por sí mismo sino su sola presencia, al modo de los fonemas en la lengua. Esta sola presencia marca necesariamente uno de los términos de la oposición correspondiente, pero este término no significa nada por sí solo. Puccinelli Converso"

\section{Pictórico complejo: semas}

Este grupo supone la utilización de algunos elementos, o de algunos optemas, del grupo anterior. Su identificación corresponde plenamente al marco de la cultura que sustenta la obra como sentido.

I. Figuración: se establecen unidades icónicas de diverso tipo, conforme a un saber cultural que condiciona la función significadora. Pueden oponerse diversas categorías, como humano/no humano, unidad/multiplicidad, aislamiento/agrupación, etc. $\mathrm{y}$ establecidas ciertas unidades pueden "figurar" otras mayores o menores por la relación que guardan con las unidades ya identificadas. Un círculo, por ejemplo, puede constítuir un ojal, una tecla, un reloj, sólo por la relación que guarda con un conjunto mayor identificable. 
Algunos detalles, identificables en segunda instancia, pueden conformar signos de primera importancia en el conjunto. Tal sucede con la gestualidad, la posición o postura, ciertos subrayados debidos a la calidad del diseño, la relación de una figura con otra.

II. Perspectiva: uso de la oposición cerca/lejos por medio de diferentes optemas: luminosidad, precisión, cromaticidad, linearidad. También se obtiene este resultado con el uso de la magnitud, oposición grande/pequeño, la cual va referida siempre a los figuremas o unidades de la figuración.

III. Conjuntos sintagmáticos: las relaciones significadoras establecidas entre figuras relacionadas son abundantes en cuanto a posibilidades. Cada pintura, sin embargo, utiliza un número muy limitado. Se construyen grupos en una relación centro/periferia, por ejemplo; pueden instituirse nexos entre diferentes grupos sintagmáticos a manera de articulaciones de un significante más complejo. Las figuras agrupadas o separadas pueden, por este solo hecho, significar relaciones muy precisas en el contexto cultural del que provienen (3).

IV. Composición es, en definitiva, un tipo de conjunto sintagmático que considera la distribución total de los figuremas y de sus interrelaciones. La composición se refiere a diversas oposiciones que es preciso deslindar: simetría/asimetría; centralización/dispersión; distinción de planos, de subordinaciones, de prioridades, etc.

Una observación se impone en este momento. El arte abstracto utiliza exclusivamen:3 los optemas del primer grupo. Sus posibilidades de sentido, en una primera aproximación, se refieren a "conceptoscprecisamentel"abstractos" mostrados en el lienzo y no significados por él. Si en un cuadro figurativo un conjunto de líneas y colores puede representar una corona, una pintura abstracta no re-presenta otra cosa, se presenta a sí misma simplemente.

Habría que reconocer aquí la posibilidad de crear combinaciones abstractas que nos remiten a ciertos conceptos, también "abstractos", como son: ritmo, equilibrio, estática, dinámica, etc. correspondientes a un segundo grado de complejidad, semejante al de los conjuntos sintagmáticos o a la composición figurativa.

(3) Un ejemplo ilustrativo lo constituye el panel central del políptico El cordero místico de los hermanos Juan y Huberto Van Eyck, cuando el políptico muestra sus hojas exteriores al estar cerrado. Las figuras de la Virgen y del Angel están representadas de rodillas. Si se pusieran de pie, no entrarían en la habitación en que se encuentran; todo esto significa, en la iconografía medieval, relaciones muy precisas de jerarquización. 
Estas "composiciones abstractas" exigen una identificación de sus unidades componentes y de las relaciones existentes entre estas unidades. La naturaleza de estas relaciones se establece al interior del sistema estructurador y significativo de lo abstracto.

\section{b) Segundo nivel: LINGUISTICO O METASEMIOTICO}

Este segundo nivel está constituido por la aplicación de la palabra a la imagen. Es esencialmente la función de nominación, correspondiente a una traducción del sistema óptico al sistema lingüístico.

La posibilidad de nombrar los signos o los significados depende del objeto en sí y de la competencia de los espectadores. Esta competencia es perfectible, como en general toda lectura, y puede, también, convertirse en incompetencia efectiva a causa de errores o abusos de interpretación de los signos.

Los signos ópticos pueden ser, en algunos casos, fácilmente nominables. Estos signos los llamamos: A. En otros casos la denominación parece imposible para el espectador concreto: signos Z.

Entre ambos extremos cabe una serie de graduaciones muy sutiles que van desde el "no sé cómo decirlo" (Z) hasta el "tiene que significar tal cosa" (A).

La graduación $\AA$ Z $Z$ no tiene que ver con el carácter abstracto o figurativo de la pintura observada. Se refiere, exclusivamente, a la posibilidad o imposibilidad para el espectador de traducir a palabras la impresión visual que ha registrado.

En un caso determinado una figuración puede ser $\mathrm{Z}$ para un espectador que desconoce elureferente, por encontrarse fuera del contexto cultural que sustenta a este signo. Por el contrario, una pintura abstracta puede ser perfectamente descrita con palabras, como en el caso de ciertos cuadros de Mondrian, sin que se omita uno solo de sus elementos, ni una sola de sus relaciones.

A propósito de estas lecturas ópticas, consideramos auténtica y legítima la expresión "no entiendo nada", que brota espontáneamente del público desconocedor del sistema en que se construyen ciertas obras. La semiótica, justamente, valoriza el ejercicio de la comprensión, ya sea figurativa o abstracta, como efecto lógico de la transmisión del sentido.

Un problema teórico se plantea en este momento. La identificación mental de los signos parece corresponder a una nominación también mental, generalmente realizada de modo automático y a velocidad no consciente, que supone la práctica más o menos atenta de la traducción lingüística. Dicho de otro modo, aunque no sean pronunciadas las palabras que corresponden mentalmente a los signos identificados, éstas han sido "citadas" mentalmen- 
te al estímulo de lo reconocido en la experiencia puramente visual. Este aspecto de la actividad humana, de carácter eminentemente psicológico, merecería un estudio minucioso.

Ciertas impresiones más o menos estéticas, producidas por la captación de los grandes conjuntos o la percepción de ciertos detalles, están fundadas principalmente por un tipo de comprensión, es decir, por un ejercicio semiótico previo. Si nos admira y entusiasma el "valor táctil de una tela" o "la distribución escalonada de los figuremas en una perspectiva", reconocemos siempre un tipo de relación significativa aunque no la podamos nombrar. La falta de expresión lingüística que se señala con la frase "no sé cómo decirlo" no corresponde a una ignorancia lingüística de lo reconocido sino, las más de las veces, a la imposibilidad de transmitir la emoción producida o a la dificultad de explicar completamente todas sus causas.

En principio todo lo registrado o comprendido es traducible al lenguaje. Sin embargo existen aspectos expresivos propios al sistema empleado, el sistema óptico en este caso, que no pueden traducirse en integridad al código lingüístico. Un caso evidente es el de las caricaturas que no pueden ser explicadas con palabras para captar todo su sentido, sino "hay que verlas" necesariamente, pues ninguna metáfora o imagen lingüísticas equivalen, en este caso, a la visión.

\section{c) Tercer nivel: METALINGUISTICO}

El tercer nivel sê constuye c: partír de la nominación o denominación lingüística oral o mental. Estamos, en esta etapa final, frente a las funciones de la connotación y $\mathrm{y}^{\mathrm{d}} \mathrm{de}$ "la intertextualidad.

El título que usualmente designa el contenido axial de nuestras pinturas tradicionales, es un mensaje lingüístico específico que se impone a la función semiótica de la imagen como ancla y como posta de relevo (4).

La "cadena flotante" de sentidos posibles que conforman una polisemia intrigante e interrogante, es cribada drásticamente por la trama de sentidos determinados por el código lingüístico del títu. lo. Esta selección es, en la mayoría de los casos, determinante y evidente. Tal sucede con la pintura neoclásica, por ejemplo. En otros casos, el surrealismo o el dadaísmo, la polisemia del código visual se multiplica al contacto del contexto lingüístico. La persistencia de la memoria de Dalí, por ejemplo, ilustra esta función de complejización.

(4) Roland Barthes: "Rhétorique de l'image". En Communications. Paris. No. 4. 1964, p. 43. 
Algunos cuadros en secuencia (Carpaccio, Rubens, Miró, etc.) obligan a una lectura intertextual que condiciona las relaciones significativas de manera definitiva.

Ciertos figuremas, sintagmas o conjuntos más o menos complejos, remite no sólo a la cultura de la que proceden inmediatomente, sino a otras culturas anteriores o contemporáneas que entran en relación con el propio contexto. Una Venus actual marca una relación explícita con todas las Venus de la historia del arte.

La connotación del autor y de su biografía personal y social suelen marcarse por la firma o por el estilo o por ambas cosas. Las relaciones condicionantes son legítimas como función de sentido, siempre que estén morcadas en el texto óptico por algún rasgo significativo que establezca fundadamente una estructura.

El marco, que encuadra generalmente toda pintura en Occidente, designa la categoría "arte", por lo tanto también ficción, estética, etc., clasificando por sí mismo los hechos culturales.

Puesto que toda obra de arte es un hecho humano y cultural, las connotaciones psicológicas, sociales, económicas, políticas, re ligiosas, ideológicas, pueden manifestarse de algún modo en una pintura concreta. Lo importante es delimitar, en cada caso, qué aspectos de estas connotaciones están presentes y de qué manera esta presencia es formalmente señalada. La relación ideológica puede marcar un status, una actuación social, una aceptación o un rechazo (recuérdense los poètes maudits y los impresionistas en su primer momento), un valor concreto existente o cusente en la sociedad.

Francastel (5) analiza, porejemplo, la secuencia intertextual: Giotto-Masolino-Massaccion para aprecicar ciertos aspectos evolutivos de la cultura occidental en su transformación de un modelo medieval a otro modemo. Sus agudas y concretas observaciones describen semióticamente este fenómeno de dinámica espiritual $\mathrm{y}$, acertadamente, comenta:

L'art este une des activités permanentes, nécessaires et spéeffiques de l'homme vivant en société. Il permet, non seulement, de noter et de communiquer des représentations acquises, mais d'en découvrir de nouvelles. Il n'est pas communication, mais institution. Il n'est pas langage, mais système de signification (6).

El texto lingüístico incluido en la imagen (ciertos íconos bizantinos, algunas pinturas cubistas, por ejemplo) funciona en los

p. 16.

(5) Pierre Francastel. La figure et le lien. Paris, Gallimard. 1967,

(6) Ibíd., p. 12. 
tres niveles señalados. La exacta valoración de estos signos insertados permite una aproximación más segura al texto inmanente $y$ al contexto de las connotaciones, por participar de ambas esferas y de los dos códigos utilizados. Palabra e imagen se funden en una realidad de función semiótica bivalente.

Finalmente, el contenido estético de una obra de arte parece ser constituido, en la perspectiva semiótica, por el placer o emoción producidos por la captación o comprensión de ciertas estructuras significativas consideradas bellas en sí mismas, en su función connotadora (la fricción semántica origen de la fruición artística), o en su relación estrictamente personal con el espectador. El goce estético tendría, por lo tanto, como fundamento gnoseológico un tipo de "sentido captado" que corresponde, por un lado, a las estructuras inmanentes de la obra que funcionan como estímulos, y por otro a la capacidad de asociación y de estructuración mental del espectador que logra este goce a partir de una lectura estructurante del sentido y de una relación con su propia experiencia sensible.

\section{Construcción de la imagen significativa}

Teniendo en cuenta, para esta parte final, un trabajo muy importante de A. J. Greimas (7), podemos señalar un probable recorrido de la construcción de los objetivos culturales de naturaleza pictórica, en su función semiótica o de significación.

Tres etapas principales:

1. Las estruaturas ptofundas que definen la manera de ser de un individuo o de una sociedad, y por ello de las condiciones de existencia de "los" objetos semióticos.

2. Las estructuras superficiales constituyen una gramática semiótica que ordena en formas discursivas los contenidos susceptibles de manifestación. Los productos de esta gramática son independientes de la expresión que los manifiesta.

3. Las estructuras de manifestación producen y organizan los significantes. Son particulares a cada sistema y son estudiadas por las estilísticas superficiales.

Invirtiendo el orden de este programa semiótico para el estudio de un caso concreto de pintura tradicional, podemos observar que:

a) El nivel de manifestación corresponde a una descripción de los optemas y de los semas de los Códigos Opticos ya estable-

(7) A. J. Greimas: "Les jeux des contraintes sémiotiques". En Du sens, p. 135. 
cidos. Los significantes se organizan, en cada pintura, de acuêtdo a las reglas posibles del código que elige el artista para concretar sus intenciones de significación.

b) Las estilísticas superficiales estudian las técnicas y modos propios de producir que caracterizan cada obra concreta, cada escuela, cada tendencia. La manera de resolver las dificultades materiales, de manipular los instrumentos operacionales, de plasmar cada elemento visual que, a manera de los fonemas lingüísticos, soportan materialmente los semas elementales $\mathrm{y}$, por ellos, toda la estructura significonte.

c) La gramática semiótica de las estructuras superficiales proviene de un primer grado de abstracción de los contenidos manifestados, los cuales al ser considerados en una organización discursiva se adscriben a un sistema semiótico general que prescinde del nivel manifestado.

La pintura temático o anecdótica, por ejemplo, introduce a este nivel, la conformación de una actancialidad más o menos completa o presupuesta ( 8 ), de roles actanciales precisos y de una transformación inscrita en un antes-después de la historia, de la que el cuadro forma parte. La adoración de los Magos, de cualquier pintor comprendido por la cultura cristicma, construye un relato y una actancialidad a partir del texto evangélico que está "ilustrando" y que, semióticamente, recubre completamente al presuponerlo. Del mismo modo, ese texto evangélico recubre la significación anecdótica del cuadro con su antes-después del relato y con la determinación organizadora de los actantes y sus actuaciones.

Puesto que las estructurás superficiales/son independientes de sus manifestaciones, podemos explicarnos la presencia de relatos idénticos significados por dos códigos diferentes: lingüístico y óptico.

d) Los objetos semióticos están condicionados a la manera de ser de los individuos que los producen, de las sociedades que condicionan a estos individuos y a sus maneras de comunicarse. La connotación y la intertextualidad no son suficientes para identificar estos condicionantes fundamentales. La inmanencia de las estructuras profundas, que establece las categorías presupuestas en el relato y las articulaciones de estas categorías, constituye ei nivel de contenido que soporta en su función fundamental, no sólo las estructuras secundarias, sino la explicación final de su presencia significativa en un universo cultural determinado.

(8) Cf. A. J. Greimas: "La structure des actants du récit". En Du sens, p. 249. 